\title{
Progressive Relaxation Training in Patients with Breast Cancer Receiving Aromatase Inhibitor Therapy-Randomized Controlled Trial
}

\author{
UMUT BAHÇACI ${ }^{1}$, Songül Atasavun Uysal $^{2}$, Zeynep Erdoğan İyigün ${ }^{3}$, Çetin Ordu ${ }^{3}$, \\ Gürsel Remzi Soybir ${ }^{4}$, and Vahit Özmen ${ }^{3}$ \\ ${ }^{1}$ Hacettepe University \\ ${ }^{2}$ Hacettepe Universitesi \\ ${ }^{3}$ Florence Nightingale Hospital \\ ${ }^{4}$ Memorial Hastanesi
}

June 25, 2021

\begin{abstract}
Background Aromatase inhibitors (AI) have positive effects on disease-free life in patients with Breast Cancer (BC); on the other hand, their side effects especially arthralgia can be observed in many of patients. This study aimed to evaluate the effectiveness of Progressive Relaxation Exercises (PRE) on the common side effects of AI in patients with BC. Methods A total of 44 patients receiving AI were allocated to the study and control groups in this randomized controlled, single-blind trial. The study group $(\mathrm{n}=22)$ performed a combined (one-day supervised, and 3 days home-based) PRE program 4 days/week, for six weeks. The control group $(\mathrm{n}=22)$ was given advice about relaxation in daily life. Data was collected initially and after 6 weeks of the intervention. Pain, quality of life (QoL) and emotional status (ES) were assessed using the Brief Pain Inventory (BPI), Functional Assessment of Chronic Illness Therapy (FACT) and Hospital Anxiety and Depression (HAD) scales, respectively. Results Pain was significantly reduced within the study group in Pain Severity $(\mathrm{p}=0.001)$ and Pain Interference $(\mathrm{p}=0.01)$ subscores. Pain was also reduced between the groups as compared using the Pain Severity $(\mathrm{p}=0.00)$ and Patient Pain Experience $(\mathrm{p}=0.003)$ sub-scores; QoL and ES remained with no significant difference either within the groups or between the groups $(\mathrm{p}>0.05)$. Conclusion The results of this study showed that PRE significantly decreased pain scores in BC patients receiving AI. Although the reduction in pain is a valuable data even in the 6-week period in those cases, the long-term effects of relaxation techniques need to be followed.
\end{abstract}

\section{Progressive Relaxation Training in Patients with Breast Cancer Receiving Aromatase Inhibitor Therapy-Randomized Controlled Trial}

\section{Abstract}

Background

Aromatase inhibitors (AI) have positive effects on disease-free life in patients with Breast Cancer (BC); on the other hand, their side effects especially arthralgia can be observed in many of patients. This study aimed to evaluate the effectiveness of Progressive Relaxation Exercises (PRE) on the common side effects of AI in patients with BC.

Methods

A total of 44 patients receiving AI were allocated to the study and control groups in this randomized controlled, single-blind trial. The study group $(\mathrm{n}=22)$ performed a combined (one-day supervised, and 3 days 
home-based) PRE program 4 days/week, for six weeks. The control group $(\mathrm{n}=22)$ was given advice about relaxation in daily life. Data was collected initially and after 6 weeks of the intervention. Pain, quality of life (QoL) and emotional status (ES) were assessed using the Brief Pain Inventory (BPI), Functional Assessment of Chronic Illness Therapy (FACT) and Hospital Anxiety and Depression (HAD) scales, respectively.

Results

Pain was significantly reduced within the study group in Pain Severity $(p=0.001)$ and Pain Interference $(\mathrm{p}=0.01)$ sub-scores. Pain was also reduced between the groups as compared using the Pain Severity $(\mathrm{p}=0.00)$ and Patient Pain Experience ( $\mathrm{p}=0.003)$ sub-scores; QoL and ES remained with no significant difference either within the groups or between the groups $(\mathrm{p}>0.05)$.

Conclusion

The results of this study showed that PRE significantly decreased pain scores in BC patients receiving AI. Although the reduction in pain is a valuable data even in the 6-week period in those cases, the long-term effects of relaxation techniques need to be followed.

Keywords: Breast Cancer, Relaxation Therapy, Aromatase Inhibitors

\section{Introduction}

Aromatase inhibitors (AI) are a class of medicines that work by blocking the aromatase enzyme, which converts androgens into estrogen. Aromatase inhibitors are used in the treatment of breast cancer to reduce levels of circulating estrogen. Less estrogen means less stimulation for the growth of estrogen receptorpositive (ER) breast cancer cells, resulting in inhibition of BC progression. Approximately $80 \%$ of all breast cancers are ER-positive. ${ }^{1,2}$

Although AI have positive effects on disease-free life, their side effects especially joint pain and stiffness can limit their use ${ }^{3-5}$ In particular, arthralgia can be observed in almost $50 \%$ of patients receiving $\mathrm{AI}^{6}$, Moreover, patients on AI can experience side effects such as cognitive dysfunctions ${ }^{7}$, anxiety and depression ${ }^{8}$, sleep problems, and fatigue ${ }^{9}$. All these adverse effects may seriously deteriorate the quality of life (QoL) of patients. ${ }^{10}$ Therefore, modulating QoL by decreasing side effects of AI has critical importance in patients with BC. ${ }^{11}$

Anxiety and depression are the two main aspects of emotional status (ES). ${ }^{12} \mathrm{ES}$ is closely related to quality of life and pain perception in patients with BC. While evaluating pain, the emotional status should be assessed carefully. ${ }^{13,14}$ Furthermore, emotional distress management is recommended as a routine part of cancer care. ${ }^{15}$

Jacobson first described progressive muscle relaxation exercises (PRE) in $1938 .{ }^{16}$ PRE is a widely used method with numerous current modifications in different health disorders. ${ }^{17,18}$ Physiological, perceptual, and behavioral positive findings of muscle relaxation were well-defined. ${ }^{19}$ Previous research had established that recommendation of relaxation exercises may reduce the severity of chemotherapy symptoms in patients receiving adjuvant chemotherapy for $\mathrm{BC} .{ }^{20}$ Physical activity such as aerobic exercise, resistance exercises, Tai Chi and yoga, seems to reduce adverse effects in patients receiving hormone therapy and improve QoL. ${ }^{21,22}$

However, the effects of PRE in patients with BC receiving AI is not well-known. This study aims to investigate the effects of PRE on arthralgia, quality of life, and emotional status in patients with $\mathrm{BC}$ receiving AI.

\section{Materials and Methods}

\section{Study design}

A two-armed, assessor-blinded, randomized controlled study was conducted. BC survivors receiving AI were randomized to the study (PRE performed) or control (no interventions) group. The medical records of the patients were collected from the Breast Cancer Center of the local hospital. Eligible patients were provided 
information about the study and invited to participate in the study via phone calls. All the assessments and exercise trainings were carried out in the Physiotherapy Department of the same hospital. Outcomes were assessed at the baseline and after 6 weeks of intervention. The required information about musculoskeletal pain and relaxation exercises were provided to all participants.

The sample size was calculated by using a previous study, which mentioned the impact of yoga on functional outcomes in breast cancer survivors with aromatase inhibitor-associated arthralgias. ${ }^{23}$ The mean and standard deviation data of the FACT-B parameter were used with a power (1-type II error) of 0.80 and a Type I error of 0.05 . Therefore, it was aimed to recruit at least 20 participants per group. In total, with a dropout rate of $30 \%$, it was estimated that 26 patients would be recruited in each group.

\section{Participants and randomization}

Post-menopausal breast cancer patients who met the inclusion criteria were identified based on a search across the medical records of Breast Cancer Center between January 2014 and July 2018. Inclusion criteria were as follows: having used AI for more than 6 months, diagnosis of breast cancer stage 1-3, being a postmenopausal woman aged under 70 years, being hormone receptor-positive, and having received approval from their physician for participating in the PRE program. The participants were excluded from the study if they had communication, neurological or orthopedic problems, participated in any physical training in the previous six months, or had a diagnosis of lymphedema.

Among 120 patients with $\mathrm{BC}$ receiving AI, who were eligible as per the study criteria, 54 participants agreed to participate in the study voluntarily after phone call. (Fig 1) Participants were invited for the baseline assessment at the hospital and the signed informed consent form was obtained from each patient before assessment.

Participants were randomly allocated to the study group $(n=27)$ or control group $(n=27)$ in 1:1 ratio by using a computer-generated list of random sequence numbers. The randomization sequence was generated by a physiotherapist using the hospital protocol number as the identifier for each participant. Before randomization, a study researcher blinded to allocation and experienced on oncologic rehabilitation examined patients for musculoskeletal pain and other disorders and made patients fill out the FACT, BPI and HAD forms. After a 6 -week intervention, the same assessor examined patients and made them fill out all the forms again.

\section{Outcome measures}

\section{Pain}

As primary outcome, The Brief Pain Inventory (BPI) assesses the severity of pain and its impact on functioning. It has three dimensions of pain assessments as follows: pain severity (BPI-PS), pain interference (BPI-PI) and patient pain experience (BPI-PPE). The validated questionnaire consists of 17 questions, which evaluate the pain location, severity, and pain status, especially in the last 24 hours. ${ }^{24}$ The validity and reliability studies were conducted for the brief pain inventory, which is frequently used in cancer patients. Scores of 3-4 are defined as mild, 5-7 as moderate and 8-10 as severe pain in this scale. ${ }^{25}$

\section{Quality of Life}

As secondary outcome, The Functional Assessment of Chronic Illness Therapy - Breast (FACT-B) instrument evaluates the all-round quality of life in patients with breast cancer and is available in many languages. The questionnaire includes five sub-scales that assess physical, social, emotional, functional and another anxiety status. It has a 27 -item general (FACT-G) scale and a 10-item breast cancer-specific scale (FACTB) in which patients evaluate their status. Patients determine an appropriate expression for themselves in the last seven days, with a 5-point scale as follows: 0: none; 1: very little; 2: slightly; 3: quite; 4: too much. Higher scores indicate a higher quality of life. The necessary permissions were obtained from the provider to access and use the validated version. ${ }^{26}$

\section{Emotional Status}


As secondary outcome, The Hospital Anxiety and Depression (HAD)scale evaluates the emotional status for physically ill patients. It consists of 14 questions 7 of which evaluate depression (HAD-D) and 7 of which consider anxiety (HAD-A). The validity and reliability studies were conducted for this Likert-type measurement. The cut-off score is $10 / 11$ for the anxiety subscale and $7 / 8$ for the depression subscale. Accordingly, any points above these scores are considered to be at risk. ${ }^{27}$

\section{Intervention}

PRE was applied on the study group after the first assessment at the hospital. PRE was practiced 4 days/week (one session was supervised; 3 sessions were home-based) during six weeks by the same physiotherapist. Each session lasted approximately 60 minutes. The home-based program was implemented with the same exercise programs, illustrated in detail on a brochure. Participants were encouraged to keep up the same program. An exercise diary was created for each patient to follow up the on the program in a regular discipline. The patients were recommended to practice exercises in a long sitting position in comfortable seats. The silence and dim light were provided to extend the effectiveness of relaxation. Then, the instructions in Table 1 were given to the patients. ${ }^{19}$

\section{$<$ Insert Table 1 here $>$}

The patients performed exercises in 5-second-long contraction and 10-second-long relaxation periods. After contractions in each exercise, the command was 'now relax' to make the participants feel the relaxation. Each exercise was performed for three times. Breathing was performed between the exercise periods to increase the effectiveness of relaxation. The participants were excluded if they missed $10 \%$ of sessions in total and failed to keep up the same program.

Participants in the control group were advised to relax by themselves in their routine life and to move away from stressful living conditions. No supervised exercises or follow-up procedures were provided for the control group. The participants were aware that they could participate in PRE programs for 6 weeks, if the study provide beneficial effects after intervention.

Both groups were informed about the patients' process and questions about the study were answered via phone calls, at the hospital during the sessions, or physician appointments.

The SPSS software (Copyright ${ }^{\circledR}$ SPSS Version 26) was used for statistical evaluation. The mean [95\% confidence intervals (CI)], standard deviations, and frequency rates were analyzed for baseline characteristics. The group distributions were examined using the Kolmogorov-Smirnov test. The group analysis was performed using the non-parametric test methods due to the low number of participants. The Mann-Whitney U test was used for the analysis of independent quantitative data, and Wilcoxon test was used for the analysis of dependent data. The McNemar test was used for dependent variables, and the Chi-Square test was used for independent variables for studying the qualitative data. Cohen's Formula was used for calculating the effect size of differences between and within the groups. The SPSS graphics were used to create figures; and a P value $<0.05$ was considered significant.

\section{Results}

After 6-week intervention sessions, 44 out of 54 (\%81.4) participants completed the assessments in both groups. (Fig. 1)

\section{$<$ Insert Figure 1 here $>$}

The groups were similar in terms of baseline characteristics, which were defined as age, body mass index (BMI), marital and educational status and type of AI used ( $>0.05)$ (Table 2).

\section{$<$ Insert Table 2 here $>$}

There was no difference in BPI, FACT and HAD scores in the initial values before the intervention for both groups $(\mathrm{p}>0.05)$. 
There was a significant reduction in BPI-PS $(\mathrm{p}=0.001)$ and BPI-PI $(\mathrm{p}=0.012)$ scores between the initial and final values in the study group. (Fig 2)

\section{$<$ Insert Figure 2 here $>$}

In contrast, the BPI-PPE, FACT-G, FACT-B, HAD-D and HAD-A scores between the initial and final values revealed no significance (all $\mathrm{p}>0.05$ ) within the group's analysis. (Table 3 )

\section{$<$ Insert Table 3 here $>$}

The analysis showed that the differences between the study and control groups were significant in terms of BPI-PS $(p=0.000)$ and BPI-PPE $(p=0.003)$ scores. No significant differences were found between the groups in terms of BPI-PI, FACT-G, FACT-B, HAD-D and HAD-A scores ( $\mathrm{p}>0.05)$. (Table 3)

\section{Discussion}

The present study has been designed to shed light on the effect of PRE as an alternative therapeutic method to reduce pain and investigate its positive impact on the quality of life $(\mathrm{QoL})$ and $\mathrm{AD}$ status in patients with BC receiving AI. Pain was significantly reduced within the study group and between groups in pain sub-scores. Musculoskeletal pain is a serious problem, which could be seen by up to $50 \%$ of patients with $\mathrm{BC}$ receiving $\mathrm{AI}^{28}$ Laroche et al. suggested that pain was a mostly psychological problem rather than being affected by genetic and biological factors. ${ }^{29}$ Presant et al. reported that therapeutic management and patient's educational background were also significant factors for pain relief. ${ }^{28}$ Our findings broadly support the work of other studies in this area linking to improve pain scores with PRE.

Pharmacological approaches have been identified as primary effective options to cope with AI-related pain in literature. At the same time, other complementary medicine strategies like acupuncture, nutritional supplementation, relaxing techniques and physical exercises are suggested as secondary options. ${ }^{30}$ Some exercise methods were previously used to reduce pain and related emotional problems with limited success in AI users. Among these, aerobic exercise, resistance exercise or methods combining physical exercise with other methods seem to be efficacious techniques to cope with pain in the literature. ${ }^{31-34}$ The present study showed that, although the pain scores of the study group were higher than the control group before the intervention, it decreased even more after PRE. This shows us that they use the relaxation technique effectively to cope with pain. Improvements in the pain scores of the PRE group corroborate the literature findings.

Yoga and Tai-Chi are reported to be relaxation techniques, which are recommended to improve wellbeing and reduce pain in patients with $\mathrm{BC}$ receiving $\mathrm{AI} .^{23,35} \mathrm{PRE}$ aims to relax most of the muscles in the form of a 'contract and relax' method, which is distinct from Tai-Chi and Yoga. PRE was performed as an exercise method to achieve muscle relaxation in the present study. Integrative therapies are recommended to reduce adverse effects of treatments, although more substantial evidence is needed to achieve a consensus for wider use. ${ }^{36,37}$ PRE should be considered as an integrative therapeutic method to reduce pain in patients with BC receiving AI.

The present study did not find a significant difference in QoL and ES outcomes with the implementation of PRE. There is no consensus in the literature on the positive effect of exercises for QOL and ES in patients with BC. Some of the literature studies suggest exercise to improve QoL and ES in patients with BC receiving AI ${ }^{38-40}$ In particular, the aerobic and resistance training seem to be effective in improving QoL and ES in AI-receiving patients with BC. ${ }^{33,34}$ On the other hand, Cadmus et al. showed that exercise did not affect QoL in either recently diagnosed or post-treatment in patients with BC. ${ }^{41}$ Therefore, QoL and ES seem to need more substantial evidence among treatments of patients with BC.

The randomized design and a high rate of technical compliance of the patients with the scheduled exercise program constitute the power of this study. Furthermore, the high rate of $(81 \%)$ adherence of the patients to the program was satisfactory during the present study. In contrast, the small sample size of the groups and short (one-day-long) supervision program in a week are its limitations. Moreover, lack of long-term follow up of participants could be considered as the absence of compliance of this study. 


\section{Conclusions}

This study indicate that supervised and home-based PRE is efficient in reducing the pain sub-scores (PS and PPE) of patients with BC receiving AI. PRE has no positive effect on QoL and AD scores. Further studies are needed to reach a consensus to recommend PRE as one of the primary and long-term treatment options for reducing AI-related pain in patients with BC. Long-term follow-up procedures may be important for future studies to ensure patient compliance with complementary therapies.

\section{References}

1. Cuzick J, Sestak I, Forbes JF, et al. Anastrozole for prevention of breast cancer in high-risk postmenopausal women (IBIS-II): an international, double-blind, randomised placebo-controlled trial. The Lancet. 2014;383(9922):1041-1048.

2. Lancet EBCTCGJT. Aromatase inhibitors versus tamoxifen in early breast cancer: patient-level metaanalysis of the randomised trials. 2015;386(10001):1341-1352.

3. Mincey BA, Duh MS, Thomas SK, et al. Risk of cancer treatment-associated bone loss and fractures among women with breast cancer receiving aromatase inhibitors. Clinical breast cancer.2006;7(2):127-132.

4. Sabel MS. Chapter 17 - Principles of Adjuvant Hormonal Therapy. In: Sabel MS, ed. Essentials of Breast Surgery. Mosby; 2009:267-278.

5. The A. Anastrozole alone or in combination with tamoxifen versus tamoxifen alone for adjuvant treatment of postmenopausal women with early breast cancer: first results of the ATAC randomised trial. The Lancet. 2002;359(9324):2131-2139.

6. Crew KD, Greenlee H, Capodice J, et al. Prevalence of joint symptoms in postmenopausal women taking aromatase inhibitors for early-stage breast cancer. Journal of Clinical Oncology.2007;25(25):3877-3883.

7. Bender CM, Sereika SM, Brufsky AM, et al. Memory impairments with adjuvant anastrozole versus tamoxifen in women with early-stage breast cancer. Menopause (New York, NY). 2007;14(6):995.

8. Breckenridge LM, Bruns GL, Todd BL, Feuerstein M. Cognitive limitations associated with tamoxifen and aromatase inhibitors in employed breast cancer survivors. Psycho-Oncology.2012;21(1):43-53.

9. So WK, Marsh G, Ling W, et al. The symptom cluster of fatigue, pain, anxiety, and depression and the effect on the quality of life of women receiving treatment for breast cancer: a multicenter study. Paper presented at: Oncology nursing forum2009.

10. Cella D, Fallowfield L, Barker P, Cuzick J, Locker G, Howell A. Quality of life of postmenopausal women in the ATAC ("Arimidex", tamoxifen, alone or in combination) trial after completion of 5 years' adjuvant treatment for early breast cancer. Breast cancer research and treatment. 2006;100(3):273-284.

11. Baglia ML, Lin IH, Cartmel B, et al. Endocrine-related quality of life in a randomized trial of exercise on aromatase inhibitor-induced arthralgias in breast cancer survivors. Cancer. 2019.

12. Snaith RP. The hospital anxiety and depression scale. Health and quality of life outcomes. 2003;1(1):1-4.

13. Harris SR, Schmitz KH, Campbell KL, McNeely ML. Clinical practice guidelines for breast cancer rehabilitation: syntheses of guideline recommendations and qualitative appraisals. Cancer.2012;118(S8):2312-2324.

14. Reyes-Gibby CC, Anderson KO, Morrow PK, Shete S, Hassan S. Depressive symptoms and health-related quality of life in breast cancer survivors. Journal of women's health. 2012;21(3):311-318.

15. Holland JC, Bultz BD. The NCCN guideline for distress management: a case for making distress the sixth vital sign. Journal of the National Comprehensive Cancer Network. 2007;5(1):3-7.

16. Jacobson E. Progressive muscle relaxation. Interview Behaviour" Journal of Abnormal Psy-University of Chicago Piess, Chicago chology. 1938;75(1):18. 
17. Bell JA, Saltikov JB. Mitchell's relaxation technique: Is it effective? Physiotherapy. 2000;86(9):473-478.

18. Bernstein DA, CARLSON CR, SCHMIDT JE. Progressive relaxation.Stress Management. 1973:88.

19. Otman A, Kose N. Egzersiz tedavisinde temel prensipler ve yontemler.Meteksan AŞ. 2006:21-51.

20. Kurt B, Kapucu S. The effect of relaxation exercises on symptom severity in patients with breast cancer undergoing adjuvant chemotherapy: An open label non-randomized controlled clinical trial.European Journal of Integrative Medicine. 2018;22:54-61.

21. Hojan K, Molińska-Glura M, Milecki P. Physical activity and body composition, body physique, and quality of life in premenopausal breast cancer patients during endocrine therapy-a feasibility study. Acta Oncologica. 2013;52(2):319-326.

22. Lu G, Zheng J, Zhang L. The effect of exercise on aromatase inhibitor-induced musculoskeletal symptoms in breast cancer survivors: a systematic review and meta-analysis. Supportive Care in Cancer.2020;28(4):1587-1596.

23. Galantino ML, Desai K, Greene L, DeMichele A, Stricker CT, Mao JJJICT. Impact of yoga on functional outcomes in breast cancer survivors with aromatase inhibitor-associated arthralgias. 2012;11(4):313-320.

24. Dicle A, Karayurt Ö, Dirimese EJPMN. Validation of the Turkish version of the Brief Pain Inventory in surgery patients. 2009;10(2):107-113. e102.

25. Cleeland C, Ryan KJA, Academy of Medicine, Singapore. Pain assessment: global use of the Brief Pain Inventory. 1994.

26. Brady MJ, Cella DF, Mo F, et al. Reliability and validity of the Functional Assessment of Cancer Therapy-Breast quality-of-life instrument. 1997;15(3):974-986.

27. Aydemir OJTPD. Hastane anksiyete ve depresyon olcegi Turkce formunun gecerlilik ve guvenilirligi. 1997;8:187-280.

28. Presant CA, Bosserman L, Young T, et al. Aromatase inhibitor-associated arthralgia and/or bone pain: frequency and characterization in non-clinical trial patients. Clinical breast cancer. 2007;7(10):775-778.

29. Laroche F, Coste J, Medkour T, et al. Classification of and risk factors for estrogen deprivation pain syndromes related to aromatase inhibitor treatments in women with breast cancer: a prospective multicenter cohort study. The Journal of Pain.2014;15(3):293-303.

30. Yang GS, Kim HJ, Griffith KA, Zhu S, Dorsey SG, Renn CL. Interventions for the Treatment of Aromatase Inhibitor-Associated Arthralgia in Breast Cancer Survivors: A Systematic Review and Meta-analysis. Cancer nursing. 2017;40(4):E26-E41.

31. DeNysschen C, Burton H, Ademuyiwa F, Levine E, Tetewsky S, O'connor T. Exercise intervention in breast cancer patients with aromatase inhibitor-associated arthralgia: a pilot study. European journal of cancer care. 2014;23(4):493-501.

32. Irwin ML, Cartmel B, Gross CP, et al. Randomized exercise trial of aromatase inhibitor-induced arthralgia in breast cancer survivors.J Clin Oncol. 2015;33(10):1104-1111.

33. Paulo TR, Rossi FE, Viezel J, et al. The impact of an exercise program on quality of life in older breast cancer survivors undergoing aromatase inhibitor therapy: a randomized controlled trial. Health and Quality of Life Outcomes. 2019;17(1):17.

34. Fields J, Richardson A, Hopkinson J, Fenlon D. Nordic walking as an exercise intervention to reduce pain in women with aromatase inhibitor-associated arthralgia: a feasibility study. Journal of pain and symptom management. 2016;52(4):548-559. 
35. Galantino ML, Callens ML, Cardena GJ, Piela NL, Mao JJ. Tai Chi for Well-being of Breast Cancer Survivors With Aromatase Inhibitor-associated Arthralgias: A Feasibility Study. Alternative Therapies in Health $\mathscr{E}$ Medicine. 2013;19(6).

36. Greenlee H, DuPont-Reyes MJ, Balneaves LG, et al. Clinical practice guidelines on the evidence-based use of integrative therapies during and after breast cancer treatment. CA: a cancer journal for clinicians. 2017;67(3):194-232.

37. Lyman GH, Greenlee H, Bohlke K, et al. Integrative therapies during and after breast cancer treatment: ASCO endorsement of the SIO clinical practice guideline. Journal of Clinical Oncology.2018;36(25):26472655 .

38. Gerritsen JK, Vincent AJ. Exercise improves quality of life in patients with cancer: a systematic review and meta-analysis of randomised controlled trials. British Journal of Sports Medicine.2016;50(13):796-803.

39. Shobeiri F, Masoumi SZ, Nikravesh A, Moghadam RH, Karami M. The impact of aerobic exercise on quality of life in women with breast cancer: a randomized controlled trial. Journal of research in health sciences. 2016;16(3):127.

40. Zhang X, Li Y, Liu D. Effects of exercise on the quality of life in breast cancer patients: a systematic review of randomized controlled trials. Supportive Care in Cancer. 2019;27(1):9-21.

41. Cadmus LA, Salovey P, Yu H, Chung G, Kasl S, Irwin ML. Exercise and quality of life during and after treatment for breast cancer: results of two randomized controlled trials. Psycho-Oncology: Journal of the Psychological, Social and Behavioral Dimensions of Cancer.2009;18(4):343-352.

Table 1. Instructions for PRE

\begin{tabular}{l}
\hline * Punch your hands and contract your forearm \\
\hline * Punch your hands, push your elbow towards the seat \\
Bend your elbows \\
Push your shoulders back \\
Press your knee down and pull your toes towards you \\
Pull your knees towards you and push your feet down \\
Tighten your hips \\
Push your head back \\
Lift your eyebrows \\
Make wrinkles on your nose \\
Tighten your teeth \\
Push your chin down \\
Close your eyes and think of good things.
\end{tabular}

Table 2. Baseline characteristics of groups

\begin{tabular}{llll}
\hline & & PRE group $(\mathrm{n}=22)$ & Control group $(\mathrm{n}=2$ \\
\hline Age (years), mean $(\mathrm{SD})$ & Age (years), mean $(\mathrm{SD})$ & $60.5(6.1)$ & $58.8(8.1)$ \\
Body mass index $\left(\mathrm{kg} / \mathrm{m}^{2}\right)$, mean $(\mathrm{SD})$ & Body mass index $\left(\mathrm{kg} / \mathrm{m}^{2}\right)$, mean $(\mathrm{SD})$ & $28.5(4.09)$ & $27.7(3.51)$ \\
Marital status $(\mathrm{n})$ & Married & 16 & 19 \\
& Single & 6 & 3 \\
Education status (n) & University & 14 & 9 \\
& High school & 3 & 9 \\
Type of AI (n) & Primary education & 5 & 4 \\
& Anastrozole & 12 & 14
\end{tabular}




\begin{tabular}{llll}
\hline & PRE group $(\mathrm{n}=22) \quad$ Control group $(\mathrm{n}=2$ \\
\hline Letrozole & 10 & 8 \\
\hline
\end{tabular}

Table 3. Intra-Group and Inter-Group Analysis for BPI, FACT, and HAD Scores at Baseline and at Intervention in Week 6

\begin{tabular}{|c|c|c|c|c|c|}
\hline $\begin{array}{l}\text { Intervention } \\
\text { outcomes }\end{array}$ & $\begin{array}{l}\text { Intervention } \\
\text { outcomes }\end{array}$ & $\begin{array}{l}\text { Study Group } \\
(\mathrm{n}=22) \text { Mean } \\
\left(\mathrm{SD}^{*}\right)\end{array}$ & $\begin{array}{l}\text { Control Group } \\
(\mathrm{n}=22) \text { Mean } \\
\left(\mathrm{SD}^{*}\right)\end{array}$ & $\begin{array}{l}\text { Significance } \\
\text { between the } \\
\text { groups }(\mathrm{p})\end{array}$ & $\begin{array}{l}\text { Effect size } \\
\text { between the } \\
\text { groups (r) }\end{array}$ \\
\hline \multirow[t]{4}{*}{ BPI-PS } & Baseline & $3.30(1.81)$ & $2.44(1.73)$ & [?] $.001^{\mathrm{b}}$ & 0.34 \\
\hline & In Week 6 & $1.81(1.49)$ & $2.9(1.82)$ & & \\
\hline & $\begin{array}{l}\text { Effects within } \\
\text { the groups } \\
\text { (Baseline to } \\
\text { Week 6) }\end{array}$ & $1.41(1.58)$ & $-0.46(1.12)$ & & \\
\hline & $\begin{array}{l}\text { Significance } \\
\text { within the } \\
\text { groups (p) }\end{array}$ & $.001^{\mathrm{a}}$ & .17 & & \\
\hline \multirow[t]{4}{*}{ BPI-PPE } & Baseline & $3.05(1.55)$ & $2.08(1.78)$ & $.003^{b}$ & 0.99 \\
\hline & In Week 6 & $2.02(1.61)$ & $2.45(1.73)$ & & \\
\hline & $\begin{array}{l}\text { Effects within } \\
\text { the groups } \\
\text { (Baseline to } \\
\text { Week 6) }\end{array}$ & $1.03(1.66)$ & $-0.3(1.12)$ & & \\
\hline & $\begin{array}{l}\text { Significance } \\
\text { within the } \\
\text { group (p) }\end{array}$ & .20 & .30 & & \\
\hline \multirow[t]{4}{*}{ BPI-PI } & Baseline & $2.80(1.86)$ & $1.73(2.05)$ & .11 & 0.49 \\
\hline & In Week 6 & $2.17(2.07)$ & $2.01(1.87)$ & & \\
\hline & $\begin{array}{l}\text { Effects within } \\
\text { the groups } \\
\text { (Baseline to } \\
\text { Week 6) }\end{array}$ & $0.6(2.21)$ & $-0.27(1.3)$ & & \\
\hline & $\begin{array}{l}\text { Significance } \\
\text { within the } \\
\text { group }(p)\end{array}$ & $.012^{\mathrm{a}}$ & .16 & & \\
\hline \multirow[t]{4}{*}{ FACT-G } & Baseline & $80.88(11.83)$ & $78.43(19.90)$ & .89 & 0.10 \\
\hline & In Week 6 & $82.92(12.75)$ & $81.34(16.71)$ & & \\
\hline & $\begin{array}{l}\text { Effects within } \\
\text { the groups } \\
\text { (Baseline to } \\
\text { Week 6) }\end{array}$ & $-2.04(9.41)$ & $-2.91(7.5)$ & & \\
\hline & $\begin{array}{l}\text { Significance } \\
\text { within the } \\
\text { group (p) }\end{array}$ & .30 & .27 & & \\
\hline \multirow[t]{2}{*}{ FACT-B } & Baseline & $106.36(17.56)$ & $104.40(26.07)$ & .88 & 0.09 \\
\hline & In Week 6 & $108.86(16.52)$ & $107.88(21.92)$ & & \\
\hline
\end{tabular}




\begin{tabular}{|c|c|c|c|c|c|}
\hline $\begin{array}{l}\text { Intervention } \\
\text { outcomes }\end{array}$ & $\begin{array}{l}\text { Intervention } \\
\text { outcomes }\end{array}$ & $\begin{array}{l}\text { Study Group } \\
(\mathrm{n}=22) \text { Mean } \\
\left(\mathrm{SD}^{*}\right)\end{array}$ & $\begin{array}{l}\text { Control Group } \\
(\mathrm{n}=22) \text { Mean } \\
\left(\mathrm{SD}^{*}\right)\end{array}$ & $\begin{array}{l}\text { Significance } \\
\text { between the } \\
\text { groups }(\mathrm{p})\end{array}$ & $\begin{array}{l}\text { Effect size } \\
\text { between the } \\
\text { groups (r) }\end{array}$ \\
\hline & $\begin{array}{l}\text { Effects within } \\
\text { the groups } \\
\text { (Baseline to } \\
\text { Week 6) }\end{array}$ & $-2.5(12.2)$ & $-3.5(9.17)$ & & \\
\hline & $\begin{array}{l}\text { Significance } \\
\text { within the } \\
\text { group (p) }\end{array}$ & .43 & .24 & & \\
\hline \multirow[t]{4}{*}{ HAD-A } & Baseline & $6.59(3.1)$ & $6.91(4.8)$ & .42 & 0.17 \\
\hline & In Week 6 & $6.0(3.0)$ & $6.73(4.4)$ & & \\
\hline & $\begin{array}{l}\text { Effects within } \\
\text { the groups } \\
\text { (Baseline to } \\
\text { Week 6) }\end{array}$ & $0.5(2.3)$ & $0.18(2.3)$ & & \\
\hline & $\begin{array}{l}\text { Significance } \\
\text { within the } \\
\text { group (p) }\end{array}$ & .56 & .82 & & \\
\hline \multirow[t]{4}{*}{ HAD-D } & Baseline & $3.41(2.3)$ & $4.5(3.9)$ & .42 & 0.03 \\
\hline & In Week 6 & $3.05(2.88)$ & $4.23(3.6)$ & & \\
\hline & $\begin{array}{l}\text { Effects within } \\
\text { the groups } \\
\text { (Baseline to } \\
\text { Week 6) }\end{array}$ & $0.36(2.9)$ & $0.27(2.7)$ & & \\
\hline & $\begin{array}{l}\text { Significance } \\
\text { within the } \\
\text { group (p) }\end{array}$ & .28 & .83 & & \\
\hline
\end{tabular}

BPI-PS: Brief Pain Inventory-Pain Severity, BPI-PPE: Brief Pain Inventory-Patient Pain Experience, BPIPI: Brief Pain Inventory-Pain Interference, FACT-G: Functional Assessment of Chronic Illness TherapyGeneral, FACT-B: Functional Assessment of Chronic Illness Therapy-Breast, HAD-A: Hospital Anxiety Depression-Anxiety, HAD-D: Hospital Anxiety Depression-Depression, ${ }^{*} S D$ : standard deviation, a: Wilcoxon Signed-Rank test $p<0.05, b$ : Mann-Whitney U Test $p<0.05$, data are reported as means of (\%95 CI) and $(S D)$

\section{Hosted file}

image1.emf available at https://authorea.com/users/422004/articles/527812-progressiverelaxation-training-in-patients-with-breast-cancer-receiving-aromatase-inhibitortherapy-randomized-controlled-trial

Figure 1. Patient Selection and Randomization [CHART][CHART]

Figure 2. Changes in BPI-PS and BPI-PI scores in groups

BPI-PS: Brief Pain Inventory-Pain Severity, BPI-PI: Brief Pain Inventory-Pain interference 